\title{
Mechanisms of Wound Healing and Disinfection in a Plasma Source for the Treatment of Comeal Infections
}

\author{
P. Brun, a, ${ }^{\text {a }}$ A. Pellizzaro, ${ }^{b}$ R. Cavazzana,,${ }^{c}$ L. Cordaro, ${ }^{c}$ M. Zuin,,${ }^{c}$ \& E. Martines ${ }^{c}$ \\ aUniversity of Padua, Department of Molecular Medicine, Unit of Histology, Padua, Italy; ${ }^{b}$ University \\ of Padua, Department of Molecular Medicine, Unit of Microbiology, Padua, Italy; 'Consorzio RFX, \\ Padua, Italy \\ *Address all correspondence to: Paola Brun, PhD, Department of Molecular Medicine, Unit of Microbiology, University \\ of Padova, Via A. Gabelli 63 I-35100 Padua, Italy; Tel.: +39 049 8272348; Fax: +39 049 8272355, E-mail: paola.brun.1@ \\ unipd.it
}

\begin{abstract}
Cold atmospheric pressure plasmas provide the potential for effective treatment of infectious keratitis, a sight-threatening process with a worldwide occurrence of 2 million cases/yr. In microbial keratitis, bacteria, fungi, viruses, or small eukaryotes penetrate and proliferate in the cornea, causing inflammation and tissue ulceration. The requirement of clinical approaches to overcome antibiotic resistance and simultaneously foster tissue healing prompted us to develop a plasma source generated by ionizing helium flow for ophthalmologic applications. Using plasma, we reported significant reductions in load of bacteria, virus, and fungi that are frequently involved in infectious keratitis. Plasma exposure induced formation of reactive oxygen and nitrogen species in human cells, accounting for the already described biological effects. Actually, nontoxic levels of reactive species elicit intracellular signals and modulate hypoxia-related gatekeeper transcriptional factors such as nuclear factor- $\mathrm{\kappa B}$ and hypoxia-inducible factor- $1 \alpha$. Together, these data make cold atmospheric pressure plasma generated by ionizing helium flow a valid approach for the treatment of infectious keratitis.
\end{abstract}

KEY WORDS: reactive oxygen and nitrogen species, microbes, fibroblast, cornea, plasma

\section{INTRODUCTION}

The cornea, the clear and transparent portion of the eye, is one of the most important structures for vision. The cornea is a thin layer that is no more than $500 \mu \mathrm{m}$ in height and consists of five morphologically and functionally distinct layers: a stratified squamous layer of epithelial cells at the very outside of the cornea; an underlying Bowman's layer composed of fibrils of collagen; stroma, which accounts for $90 \%$ of the cornea's thickness and is mainly comprised of collagen and keratocytes; a basement membrane; and a monolayer of endothelial cells. ${ }^{1}$ In the cornea, these layers create the outer surface of the eye and are strategically placed as the first-line of defense to form an anatomical and physiological barrier against environmental stressors such as microbes. Bacteria, fungi, viruses, or small eukaryotes may directly infect the cornea or complicate traumatic injuries or underlying ocular diseases. Indeed, inappropriate use of contact lenses, irritants and allergens, or the ocular manifestation of a systemic disease (e.g., diabetes, hypertension) frequently result in laceration of the cornea and allow the entrance of microbes. 
Thus, either directly or secondarily to underlying diseases, microbial infections are the most important cause of corneal damage and visual loss impairment, conditions affecting more than 285 million individuals worldwide., ${ }^{2,3}$

Microbes proliferating in the cornea cause tissue inflammation and ulceration, namely keratitis, which progresses rapidly from red watery eyes to suppurative infection and eventually loss of corneal transparency. Patients suffering from infectious keratitis undergo a standard therapeutic protocol, receiving a concoction of broad-spectrum antibiotics. However, unsuitable drug concentration at the corneal surface, occurrence of polymicrobial infection, or infection caused by antibiotic-resistant bacteria impair topical or systemic therapies. ${ }^{4}$ Indeed, retrospective studies of cohorts of patients suffering from keratitis have identified bacterial isolates with reduced sensitivity to antibiotics such as methicillin, gentamicin, cefuroxime, ciprofloxacin, and fluoroquinolone. ${ }^{5,6}$ Moreover, because the eye does not contain blood or lymph vessels and possesses an inherent immune privilege, any recruitment of suppressive immune cells able to dampen inflammation is negligible. ${ }^{7}$ As a result, it is estimated that more than $40 \%$ of patients suffering from keratitis report a poor outcome at the close of antibiotic therapy, with loss of visual acuity. In the most severe infections, corneal transplantation or ocular enucleation is unavoidable. ${ }^{8,9}$

The urgency to treat ocular infection and sustain the wound-healing process in the cornea prompted our group and other laboratories to consider low-temperature atmospheric pressure plasma as a novel therapeutic strategy in ophthalmology, independent of the type of microbe causing the infection. ${ }^{10-12}$

\section{MATERIALS AND METHODS}

\section{A. Plasma Source}

Plasma was produced by applying a radio-frequency (RF) electric field to a flow of helium at atmospheric pressure. Due to the specific setup of the plasma, the biological samples were exposed to the plasma afterglow enriched in reactive chemical species that was generated by mixing ambient air with the helium flow. ${ }^{13,14}$ The plasma source was made up of two coaxial tubes: an inner tube of insulating material and an electrically grounded outer tube of copper. Each tube was closed at one end by a brass grid that was positioned $1 \mathrm{~mm}$ away from the other. The grids acted as electrodes, and plasma was generated in the space between the two grids by applying an RF voltage difference supplied by an RF generator coupled to the source by a matching network. The matching network increased the voltage to a value of $\sim 1000 \mathrm{~V}$ peak to peak, which was required for helium breakdown. Despite the high voltage value, the current flowing in the plasma was so low that the dissipated power was below $1 \mathrm{~W}$. The chosen operational frequency was $4.8 \mathrm{MHz}$; the gas flow rate was $1.5 \mathrm{~L} / \mathrm{min}$.

\section{B. Cell Cultures}

Vero cells and human fibroblasts were grown at $37^{\circ} \mathrm{C}$ in Dulbecco's modified Eagle's 
medium (Gibco) containing 10\% volume/volume (v/v) fetal bovine serum, 2 mm L-glutamine, $1 \mathrm{~mm}$ sodium pyruvate, $0.1 \mathrm{~mm}$ nonessential amino acids, $100 \mathrm{U} / \mathrm{mL}$ penicillin, $100 \mathrm{mg} / \mathrm{mL}$ streptomycin, and $2 \mathrm{ng} / \mathrm{mL}$ fungizone (Gibco). At confluence, cells were detached using $0.05 \%$ trypsin-ethylenediaminetetraacetic acid (Gibco) and seeded in 24-well tissue culture plates (Corning) at $3 \times 10^{5}$ cells/well. As described, cells were treated for $15 \mathrm{~min}$ with $5 \mathrm{~mm} \mathrm{~N}$-acetyl L-cysteine (NAC; Sigma-Aldrich) to reduce formation of reactive oxygen species (ROS). Cells were incubated with $200 \mu \mathrm{L}$ of fresh culture medium and exposed to the plasma afterglow generated by the plasma tip located $1.5 \mathrm{~mm}$ away for $30,60,120$, and $300 \mathrm{~s}$.

\section{Mic robial Cultures}

The effects of plasma were studied on Gram-positive bacteria (methicillin-sensitive Staphylococcus aureus [MSSA], methicillin-resistant S. aureus [MRSA], Staphylococcus epidermidis, Streptococcus pyogenens, and Streptococcus pneumoniae), Gram-negative bacteria (Escherichia coli, vancomycin-resistant [E. coliVR], Pseudomonas aeruginosa, Proteus mirabilis, and Klebsiella pneumoniae), and fungi (Candida albicans and Aspergillus fumigatus). Microbial strains were purchased from American Type Culture Collection or isolated from human specimens and identified by gas chromatography and antibiotic susceptibility tests. All microbial strains were stored at $-80^{\circ} \mathrm{C}$ and cultured overnight in Mueller-Hinton broth at $37^{\circ} \mathrm{C}$ (bacteria) or $35^{\circ} \mathrm{C}$ (fungi). Mueller-Hinton agar or Sabouraud agar were used as the solid growth medium, where appropriate.

Microbial suspensions from overnight culture were prepared in sterile phosphatebuffered saline (PBS) or artificial tear fluid ( $0.5 \%$ chicken egg lysozyme and $0.1 \%$ mucine in human serum [Sigma-Aldrich]). ${ }^{15}$ Each sample was adjusted to an optical density equivalent of $1 \times 10^{8}$ colony-forming units $(\mathrm{CFU}) / \mathrm{mL}$. Aliquots $(200 \mu \mathrm{L})$ from each bacterial suspension were exposed for $30,60,120$, and $300 \mathrm{~s}$ to the plasma afterglow generated by the plasma tip that was located $1.5 \mathrm{~mm}$ away. After plasma exposure, each sample was properly diluted in sterile PBS and immediately dispersed on solid growth medium to determine surviving cell viability using the colony count method. Samples were tested in triplicate.

Vero cells were infected with Herpes simplex virus type 1 (HSV-1) strain 17 at the multiplicity of infection 1:10. Two hours later, unabsorbed viral particles were removed. Cells were then exposed to plasma as described above. The appearance of viral-related plaques on the Vero cell monolayers was assessed $24 \mathrm{~h}$ later and expressed as plaqueforming units (PFU)/well.

\section{Intracellular Reactive Oxygen and Nitrogen Species}

To detect intracellular ROS or nitrogen species, human fibroblasts were incubated with $10 \mathrm{~mm}$ 2',7'-dichlorodihydrofluorescein diacetate (H2DCFDA; Molecular Probes, Invitrogen) or $5 \mu \mathrm{M}$ 4,5-diaminofluorescein (DAF-FM) diacetate (Molecular Probes), respectively. Cells were then incubated for $30 \mathrm{~min}$ at $37^{\circ} \mathrm{C}$ and exposed to plasma. Intracellular 
levels of ROS or N were measured 5 min later using Becton Dickinson FACSCalibur flow cytometer. Ten thousand events were acquired for each sample. The results were analyzed using Windows multiple document interface (version 2.9) for flow cytometry software.

\section{E. Westem BlotAnalysis}

Plasma-treated human fibroblasts were cultured for 4,8 , or $12 \mathrm{~h}$. Cells were then washed with ice-cold PBS and subjected to total protein extraction using nondenaturing radioimmunoprecipitation assay buffer $(150 \mathrm{~mm} \mathrm{NaCl}, 50 \mathrm{~mm}$ Tris $\mathrm{HCl}, 0.25 \%$ sodium deoxycholate, $0.1 \%$ Nonidet P-40 [Sigma-Aldrich], $100 \mu \mathrm{m} \mathrm{NaVO}, 1$ mм NaF, 1 mм phenylmethylsulfonyl fluoride, $10 \mu \mathrm{g} / \mathrm{mL}$ aprotinin, and $10 \mu \mathrm{g} / \mathrm{mL}$ leupeptin). Samples were incubated for $45 \mathrm{~min}$ on ice. Particulate material was then removed by centrifugation $\left(15,000 \mathrm{~g}\right.$ for $5 \mathrm{~min}$ at $\left.4^{\circ} \mathrm{C}\right)$, and protein concentrations were determined in the supernatants using the bicinchoninic acid method (Pierce). Proteins $(20 \mu \mathrm{g} /$ line) were separated in $10 \%$ weight $/ \mathrm{v}(\mathrm{w} / \mathrm{v})$ sodium dodecyl sulfate-polyacrylamide gel electrophoresis and finally transferred to a polyvinylidene difluoride membrane (BioRad, Italy). Membranes

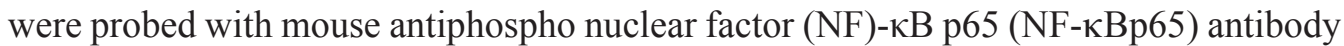
and mouse anti-hypoxia-inducible factor- $1 \alpha$ (anti-HIF-1 $\alpha$ ) antibody (cell signaling) for $16 \mathrm{~h}$ at $4{ }^{\circ} \mathrm{C}$ and then incubated with horseradish peroxidase-conjugated secondary antibody. Anti-NF- $\kappa$ B or anti- $\beta$-actin antibody (Sigma-Aldrich) was used as a loading control. Immunocomplexes were visualized using enhanced chemiluminescence (Millipore). Images were captured using multipurpose hyperfilm (Sigma-Aldrich).

\section{F. Statistical Analyses}

We present data as mean values \pm the standard error of mean for at least three experiments. The unpaired Student's $t$-test was used to compare the data of two groups. Statistical analysis was performed using GraphPad Prism 3.03 (La Jolla, California), and values of $p<0.05$ were regarded to be significant.

\section{RESULTS}

\section{A. Plasma Exposure Inactivated Bacteria and Fungi in a Time-Dependent Manner}

Exposure to the afterglow originating from the plasma source successfully inactivated a broad range of microbes, namely Gram-negative and -positive bacteria, fungi, and replicating virus. Bacteria $\left(2 \times 10^{7} \mathrm{CFU}\right)$ in sterile $\mathrm{PBS}$ were exposed to plasma for different amounts of time. The antimicrobial effect was evaluated by counting the surviving microbial colonies on agar plates. As reported in Fig. 1A, plasma treatment reduced the number of colonies of Gram-positive bacteria with an effect that was related to time of plasma exposure. Indeed, 1 min of plasma treatment significantly reduced the 

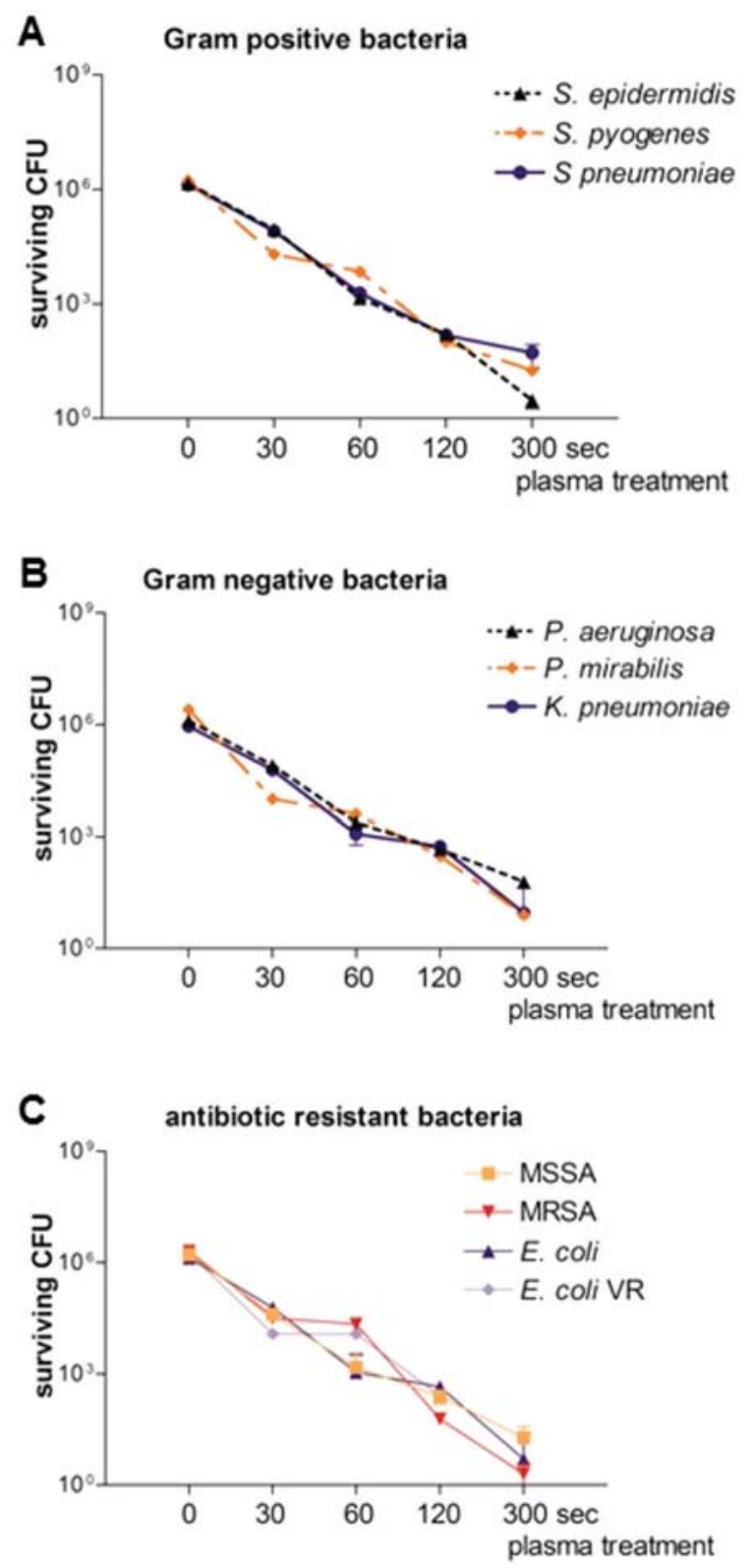

FIG. 1: Inactivation of Gram-positive (A) and Gram-negative (B) bacteria by helium-generated cold plasma. Gram-positive and -negative bacteria or antibiotic-resistant strains $(\mathrm{C})$ were prepared in sterile PBS $\left(2 \times 10^{7} \mathrm{CFU}\right)$ and exposed to plasma afterglow for 30, 60, 120, and $300 \mathrm{~s}$. After plasma exposure, each sample was properly diluted in sterile PBS and immediately dispersed on solid growth media. Surviving bacteria were determined by counting the colonies. Data are reported as mean \pm standard error; $n=3$. MSSA: Methicillin-sensitive Staphylococcus aureus; MRSA: methicillin-resistant S. aureus; E. coliVR: vancomycin-resistant Escherichia coli.

Volume 7, Issue 2, 2017 
survival of most of the bacterial species analyzed, even when increased inactivation was observed following a greater amount of plasma exposure. The same tendency was observed also for Gram-negative bacteria (Fig. 1B). Plasma treatment was equally effective in inactivating antibiotic-resistant bacteria such as MRSA and E. coliVR (Fig. 1C).

In the described experiments, bacteria that were exposed to plasma were prepared and treated in PBS, a medium that greatly differs in composition from tear fluid at the ocular surface. To create a more realistic environment, in a parallel set of experiments bacteria were prepared in an organic load that mimicked tear fluid. As reported in Fig. $2 \mathrm{~B}$, the artificial tear fluid did not affect the antimicrobial performance of the plasma on Gram-negative bacteria, but it reduced the surviving Gram-positive bacteria by 1 log (Fig 2A). Indeed, lysozyme, a component of the artificial tear fluid, damages the bacterial cell wall by catalyzing hydrolysis of $1,4-\beta$ linkages between $N$-acetylmuramic acid and $\mathrm{N}$-acetyl-D-glucosamine residues in the peptidoglycan, the most abundant polymer in the outer surface of Gram-positive bacteria.

The disinfectant effect of the plasma was also evident against the two fungal strains C. albicans and A. fumigatus (Fig. 3A). As reported for Gram-negative bacteria, the composition of the medium did not affect the antifungal properties of plasma. Indeed, the reduction in surviving colonies was comparable among fungal strains prepared in PBS and artificial tear fluid (Fig. 3B).

\section{B. Plasma Exposure Inactivated Replicating HSV-1}

As we previously reported, ${ }^{10}$ plasma treatment of HSV-1 did not reduce infectivity. Indeed, the enveloped HSV-1 is intrinsically resistant to environmental factors such as drying, ultraviolet radiation, or oxidative stress and persists for hours on inanimate surfaces. ${ }^{16}$ On the contrary, during its replication inside eukaryotic cells HSV-1 loses the
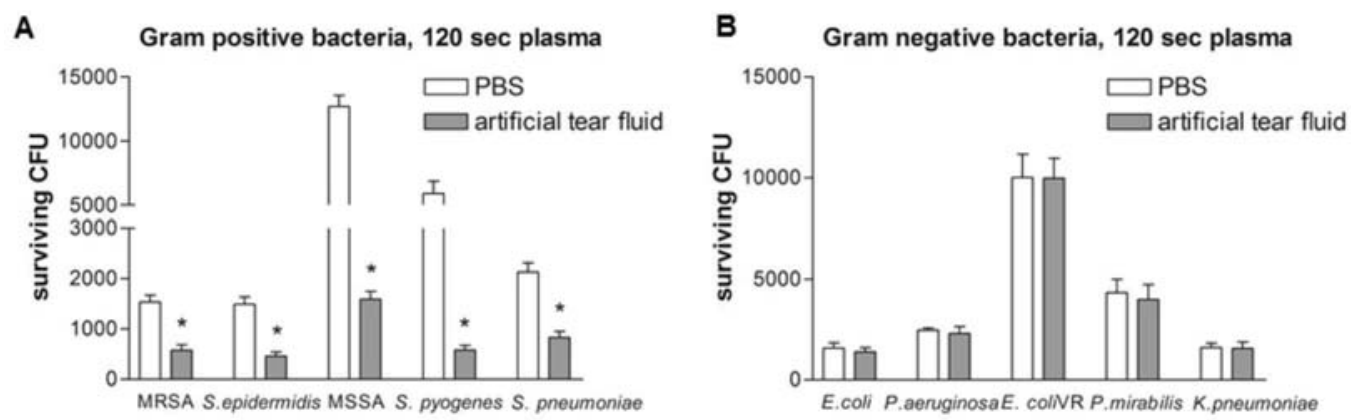

FIG. 2: Increased antibacterial effect of plasma toward Gram-positive bacteria in artificial tear fluid. Gram-positive (A) and -negative (B) bacteria $\left(2 \times 10^{7} \mathrm{CFU}\right)$ were prepared in sterile PBS or artificial tear fluid $(0.5 \% \mathrm{w} / \mathrm{v}$ chicken egg lysozyme, $0.1 \% \mathrm{w} / \mathrm{v}$ mucine, human serum $)$. Bacteria were exposed to plasma afterglow for $120 \mathrm{~s}$ and immediately dispersed on solid growth media. Surviving bacteria were determined by counting the colonies. Data are reported as mean \pm standard error; $n=3 .{ }^{*} p<0.05$ vs the same bacterial strain prepared in PBS. 

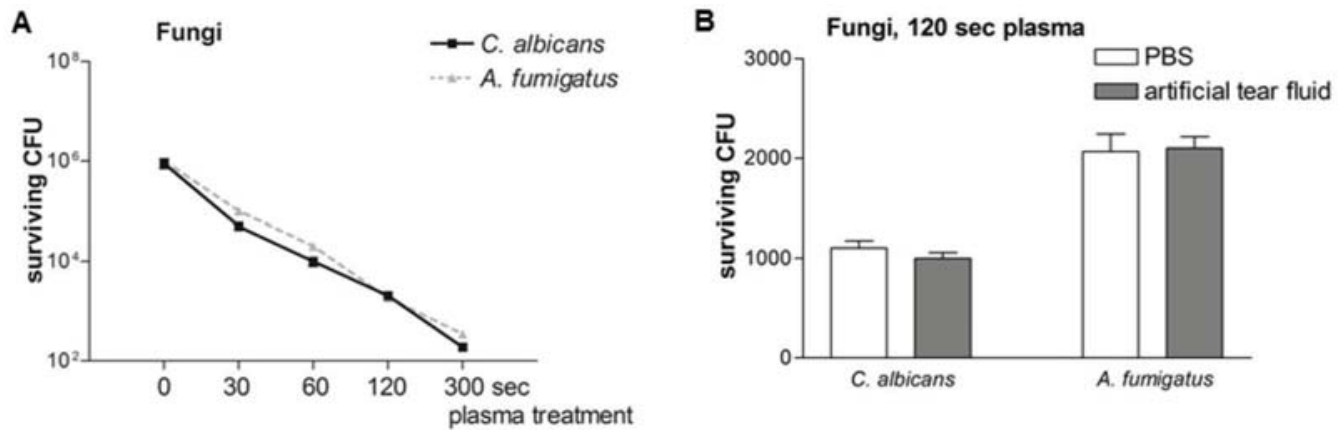

FIG. 3: Inactivation of fungi by helium-generated cold plasma. Fungi $\left(2 \times 10^{7} \mathrm{CFU}\right)$ were prepared in sterile PBS (A) or sterile artificial tear fluid (B). Microbes were then exposed to the plasma afterglow for 30, 60, 120, and $300 \mathrm{~s}$ (A) or $120 \mathrm{~s}$ only (B). After plasma exposure, each sample was properly diluted in sterile PBS and immediately dispersed on solid growth media. Surviving bacteria were determined by counting the colonies. Data are reported as mean \pm standard error; $n=3$.

envelope and becomes more sensitive to cellular stressors. For this reason, permissive Vero cells were infected with HSV-1 $\left(2 \times 10^{6} \mathrm{PFU} /\right.$ well $)$ and then exposed to plasma. As reported in Fig. 4, plasma treatment significantly reduced the occurrence of cytopathic effects on infected Vero cells (reported in PFU), demonstrating a reduction in the presence of replicating and infecting HSV-1. As a control, when suspensions of HSV-1

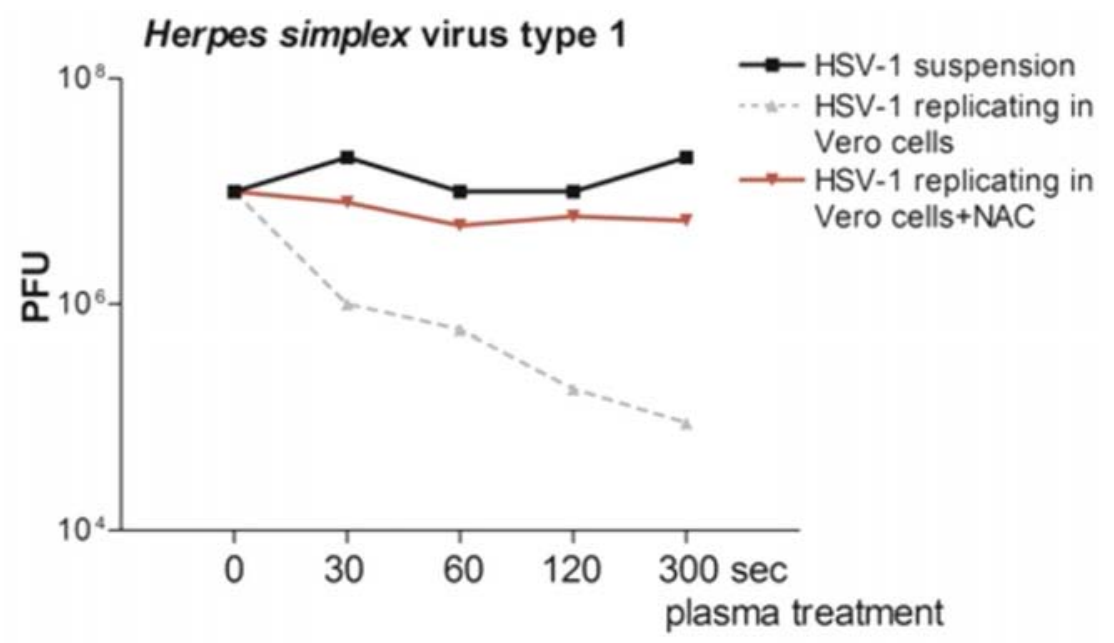

FIG. 4: Plasma exposure inactivated replicating HSV-1. Vero cells were infected with HSV-1 $\left(2 \times 10^{6} \mathrm{PFU}\right)$ and treated (middle line) or not (bottom line) with $5 \mathrm{~mm} \mathrm{NAC}$, a ROS scavenger. Infected cells were then exposed to plasma afterglow for 30,60, 120, and $300 \mathrm{~s}$. Alternatively, HSV-1 was exposed to plasma and then used to infect Vero cells (black line). Cells were incubated for $24 \mathrm{~h}$. Replication of HSV-1 was evaluated by the appearance of the cytopathic effect on the Vero cell monolayer and expressed as PFU. Data are reported as mean \pm standard error; $n=3$.

Volume 7, Issue 2, 2017 
$\left(2 \times 10^{6} \mathrm{PFU}\right.$ in $\left.200 \mu \mathrm{L}\right)$ were directly treated with plasma and then incubated with Vero cells, no antiviral effects were observed. Suppression of HSV-1 correlated with generation of ROS in Vero cells. Indeed, pretreatment of infected cells with NAC, a ROS scavenger, significantly dampened the antiviral effect.

\section{Plasma Treatment Generated Reactive Oxygen and Nitrogen Species in Human Fibroblasts}

Our previous studies demonstrated that exposure to the afterglow of helium cold plasma generated ROS in biological samples and, moreover, that ROS are involved in the plasma-induced biological effects. ${ }^{10}$ However, several studies also reported that reactive nitrogen species (RNS) are equally important to the therapeutic effects of cold plasma. ${ }^{17}$ Therefore, in this study generation of reactive oxygen and nitrogen species (RONS) was evaluated in human fibroblasts loaded with H2DCFDA or DAF-FM to detect ROS and RNS, respectively. As seen in Fig. 5, exposure to plasma for 5 min generated RNS in human fibroblasts. Kinetics of the RNS levels paralleled ROS, peaking 5 min after plasma exposure and then decreasing in $2 \mathrm{~h}$ to near basal levels.

\section{Plasma Exposure Induced Intracellular Signaling in Human Fibroblasts}

Although historically viewed as purely harmful, new evidence suggests that the level of RONS regulates important intracellular signaling pathways. Thus, the physiologi-

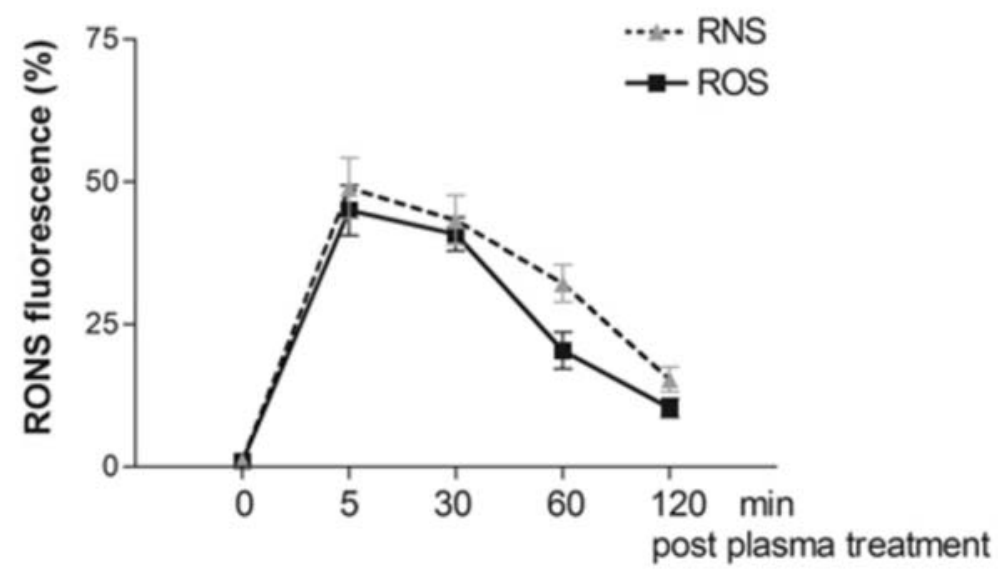

FIG. 5: Plasma treatment generated RONS in human fibroblasts. Human fibroblasts were incubated with $10 \mathrm{~mm}$ H2DCFDA (solid line) or $5 \mu \mathrm{M}$ DAF-FM (dotted line) to detect intracellular ROS or RNS, respectively. Cells were then exposed to plasma afterglow for 30,60, 120, and $300 \mathrm{~s}$; collected 5 min later; and analyzed by fluorescence-activated cell sorting. ROS and RNS formation were reported as the percentage of fluorescence-positive cells. Data are reported as mean \pm standard error; $n=6$. 
cal concentration of RONS fosters cell growth and proliferation, whereas higher levels result in cell damage or tumor transformation. ${ }^{18}$ The specific effects of RONS are modulated largely through the activation of hypoxia-related gatekeeper transcriptional factors

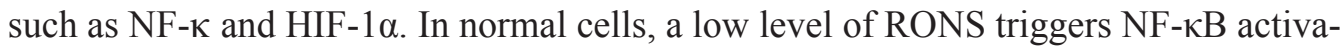
tion through serine phosphorylation of p65 and promotes transcription of antiapoptotic and anti-inflammatory genes. ${ }^{19}$ In contrast, a high level of RONS exhausts intracellular oxygen and results in HIF- $1 \alpha$ accumulation and cell death. ${ }^{20}$

To assess intracellular signaling, human fibroblasts were exposed to the afterglow of plasma for $5 \mathrm{~min}$. Phosphorylation of the NF-кBp65 subunit on serine 536 and increased expression of HIF- $1 \alpha$ were evaluated by western blot analysis at 4, 8, and $12 \mathrm{~h}$. As shown in Fig. 6, plasma exposure did not increase expression of HIF-1 $\alpha$ in human fibroblasts, thus preventing hypoxia-related cell damage. On the other hand, at $4 \mathrm{~h}$ after exposure plasma elicited phosphorylation of NF- $\mathrm{KB}$ p65, accounting for the cell proliferation we previously described. ${ }^{14}$ However, the intracellular signal induced by plasma is time limited, because we did not find activation of NF- $\mathrm{KB}$ to be increasingly evident $8 \mathrm{~h}$ after plasma exposure.

\section{CONCLUSIONS}

Infectious keratitis is a sight-threatening disease that results from microbial colonization of the outer ocular surfaces. According to recent reports, Gram-positive bacteria such as $S$. aureus and S. epidermidis are mainly involved in infectious keratitis. Gram-negative bacteria ( $E$. coli, $P$. aeruginosa) are isolated in $\sim 25 \%$ of culturally positive ophthalmic specimens and frequently associated with severe inflammation and poor outcome. Vi-

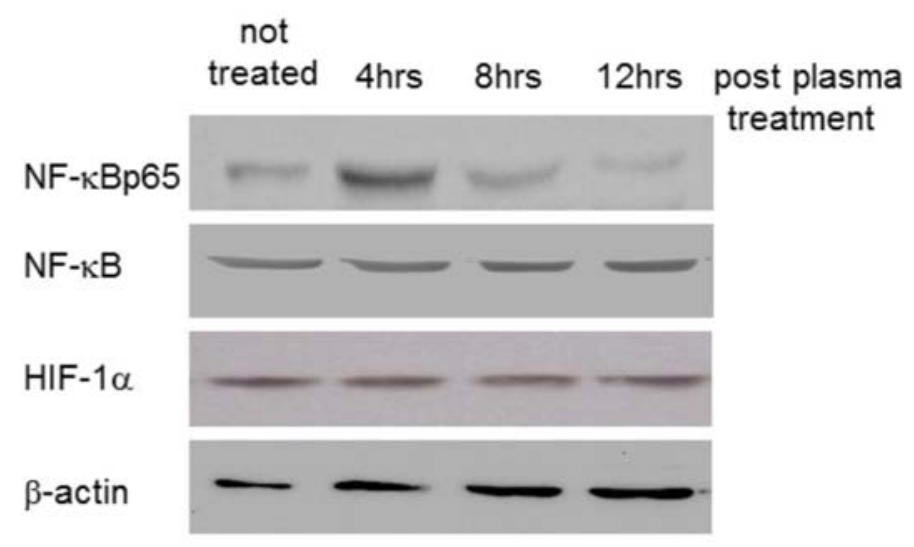

FIG. 6: Plasma exposure triggered intracellular signaling in human fibroblasts. Human fibroblasts were exposed to plasma for $5 \mathrm{~min}$. Following 4, 8, or $12 \mathrm{~h}$, cells were collected and proteins extracted. Phosphorylation of NF- $\mathrm{kBp} 65$ and increased expression of HIF-1 $\alpha$ were assessed by western blot analysis on protein extracts. Total NF- $\kappa \mathrm{B}$ and $\beta$-actin antibodies were used as loading controls. Data are representative of two independent experiments with similar results.

Volume 7, Issue 2, 2017 
ruses such as HSV-1, fungi (C. albicans, A. fumigatus, and Fusarium spp), and protozoa are less frequent, but their clinical importance is growing due to the increasing amount of individuals wearing contact lens.

We previously demonstrated that atmospheric pressure cold plasma generated by ionizing a helium flow mixed with ambient air selectively inactivated different microbes without damaging host cells. These observations foster the idea of therapeutic applications for plasma in ophthalmology, because it represents a great advantage in the treatment of polymicrobial infections of the cornea. Indeed, microbial infection very often complicates any type of corneal damage. Thus, patients suffering from keratitis undergo specimen collection for microbiological studies and simultaneously begin a standard therapeutic protocol with a broad range of antibiotics at high concentration, even before the microbiological results are available. Unfortunately, as revealed by several clinical studies the occurrence of polymicrobial infections (e.g., from bacteria and fungi) and the emerging antibioticresistant bacterial strains make the antibiotic treatment inappropriate for some patients.

It is now well accepted that the antimicrobial effect of plasma is largely mediated by the generation of reactive species ${ }^{10}$ and therefore unrelated to the type of microbe involved in the infectious process and the antibiotic resistance of bacteria. In the present study, we also demonstrated that the composition of the medium soaking the bacteria affects the microbicidal efficacy of the plasma, increasing the antibacterial effects toward Gram-positive bacteria. Thus, unlike the culture media or PBS frequently used to prepare microbes for disinfectant assessment of plasma, tear fluid includes mucin that mixes with microbes to reduce their motility and lysozyme that enzymatically attacks the peptidoglycans, largely present in the wall of Gram-positive bacteria. Moreover, as emphasized in several previous studies, ${ }^{21}$ proteins and amino acids abounding in tear fluid increase the generation of oxygen and nitrogen species, thus contributing to the disinfectant effects of the plasma.

Host cells are instead protected from the oxidative burst generated by plasma exposure. Indeed, in the host cells antioxidant enzymes, thiol-enriched proteins, compartmentation of cytoplasmic organelles in intracellular membranes, or segregation of nucleic acids into the nucleus avoid the amplification loop cascade for RONS generation and excessive production of highly reactive species. Indeed, physiologically quenched nontoxic levels of reactive species elicit intracellular messengers and tightly modulate cell growth and wound healing. Beyond the concentration of reactive species that are not increasingly controlled by the reducing capacity of the cells, hypoxia and cell death may occur. Because the threshold differs among cell populations, identifying cellular markers to monitor the dangerous concentration of RONS is mandatory. In this study, we suggested two cellular markers acting as reactive species-related gatekeeper tran-


RONS resulting in cell growth, whereas HIF-1 $\alpha$ accumulates under hypoxic conditions. Of course, several other cellular markers are suitable for monitoring the cellular effects of RONS generated by plasma, and additional studies are required to validate their use in the ophthalmic application of plasma. 


\section{REFERENCES}

1. Richardson A, Wakefield D, Di Girolamo N. Fate mapping mammalian corneal epithelia. Ocular Surf. 2016;14:82-99.

2. Yam JC, Kwok AK. Ultraviolet light and ocular diseases. Int Ophthalmol. 2014;34:383-400.

3. Bourcier T, Scheer S, Chaumeil C, Morel C, Borderie V, Laroche L. Fungal and bacterial chronic endophthalmitis following cataract surgery. Br J Ophthalmol. 2003;87:372-3.

4. Grundmann H, Aires-de-Sousa M, Boyce J, Tiemersma E. Emergence and resurgence of methicillinresistant Staphylococcus aureus as a public-health threat. Lancet. 2006;368:874-85.

5. Chang VS, Dhaliwal DK, Raju L, Kowalski RP. Antibiotic resistance in the treatment of Staphylococcus aureus keratitis: A 20-year review. Cornea. 2015;34:698-703.

6. Shalchi Z, Gurbaxani A, Baker M, Nash J. Antibiotic resistance in microbial keratitis: Ten-year experience of corneal scrapes in the United Kingdom. Ophthalmology. 2011;118:2161-5.

7. Benhar I, London A, Schwartz M. The privileged immunity of immune privileged organs: The case of the eye. Front Immunol. 2012;3:296.

8. Bourcier T, Thomas F, Borderie V, Chaumeil C, Laroche L. Bacterial keratitis: Predisposing factors, clinical and microbiological review of 300 cases. Br J Ophthalmol. 2003;87:834-8.

9. Badenoch PR, McDonald PJ, Coster DJ. Effect of inflammation on antibiotic penetration into the anterior segment of the rat eye. Invest Ophthalmol Vis Sci. 1986;27:958-65.

10. Brun P, Brun P, Vono M, Venier P, Tarricone E, Deligianni V, Martines E, Zuin M, Spagnolo S, Cavazzana R, Cardin R, Castagliuolo I, Valerio AL, Leonardi A. Disinfection of ocular cells and tissues by atmospheric-pressure cold plasma. PLoS ONE. 2012;7:e33245.

11. Alekseev O, Donovan K, Limonnik V, Azizkhan-Clifford J. Nonthermal dielectric barrier discharge (DBD) plasma suppresses herpes simplex virus type 1 (HSV-1) replication in corneal epithelium. Transl Vis Sci Technol. 2014;3:2.

12. Heaselgrave W, Shama G, Andrew PW, Kong MG. Inactivation of Acanthamoeba spp. and other ocular pathogens by application of cold atmospheric gas plasma. Appl Environ Microbiol. 2016;82:3143-8.

13. Martines E, Zuin M, Cavazzana R, Gazza E, Serianni G, Spagnolo S, Spolaore M, Leonardi A, Deligianni V, Brun P, Aragona M, Castagliuolo I, Brun P. A novel plasma source for sterilization of living tissues. New J Phys. 2009;11:115014.

14. Brun P, Pathak S, Castagliuolo I, Palù G, Brun P, Zuin M, Cavazzana R, Martines E. Helium generated cold plasma finely regulates activation of human fibroblast-like primary cells. PLoS ONE. 2014;9:e104397.

15. Hildebrandt C, Wagner D, Kohlmann T, Kramer A. In-vitro analysis of the microbicidal activity of 6 contact lens care solutions. BMC Infect Dis. 2012;12:241.

16. Firquet S, Beaujard S, Lobert P-E, Sané F, Caloone D, Izard D, Hober D. Survival of enveloped and non-enveloped viruses on inanimate surfaces. Microbes Environ. 2015;30:140-4.

17. Graves, DB. Oxy-nitroso shielding burst model of cold atmospheric plasma therapeutics. Clin Plasma Med. 2014;2:38-49.

18. Weidinger A, Kozlov AV. Biological activities of reactive oxygen and nitrogen species: Oxidative stress versus signal transduction. Biomolecules. 2015;5:472-84.

19. Takada Y, Mukhopadhyay A, Kundu GC, Mahabeleshwar GH, Singh S, Aggarwal BB. Hydrogen peroxide activates NF- $\kappa B$ through tyrosine phosphorylation of I $\kappa \mathrm{B} \alpha$ and serine phosphorylation of p65: Evidence for the involvement of I $\mathrm{B} \alpha \alpha$ kinase and Syk protein-tyrosine kinase. J Biol Chem. 2003;278:24233-41.

20. Weidemann A, Johnson RS. Biology of HIF-1 $\alpha$. Cell Death Differ. 2008;15:621-7.

21. Kalghatgi S, Kelly CM, Cerchar E, Torabi B, Alekseev O, Fridman A, Friedman G, Azizkhan-Clifford J. Effects of non-thermal plasma on mammalian cells. PLoS ONE. 2011;6:e16270.

Volume 7, Issue 2, 2017 